\title{
The Role of Interactive Visual Art Learning in Development of Young Children's Creativity
}

\author{
Sylvia Stavridi \\ Special Libraries Directorate, Bibliotheca Alexandrina, Alexandria, Egypt \\ Email: sylvia.stavridi@bibalex.org
}

Received 6 October 2015; accepted 7 December 2015; published 10 December 2015

Copyright (C) 2015 by author and Scientific Research Publishing Inc. This work is licensed under the Creative Commons Attribution International License (CC BY). http://creativecommons.org/licenses/by/4.0/

(c) () Open Access

\begin{abstract}
Learning by interactive arts methods is a non-traditional approach to new creative teaching methods, in which young children are simultaneously engaged to feel and understand the original concept of core content areas in education, such as science, technology and math from a broad perspective. This article is an attempt to investigate the question of "how to keep young children's creativity alive". It focuses on the visual art and its inter-relation between interactivity and creativity, and how the exploration of arts shapes new ways for our children to improve their practice and interaction in an increasingly intelligent setting. The article explores different digital platforms, tools, art-tech/software, and web-based applications that support the benefits of innovative active learning, and which differentiate teaching methods in traditional classes. The author confers that recently, integrated digital aesthetic learning has shifted the focus from not only fulfilling the existing education system, but also developing new interactive environmentally-friendly education, where educators are encouraged to design and build a creative digital curriculum to engage their students in a constructive way, both formally and informally. Furthermore, it discusses how arts and humanities-based initiatives are taking a prominent place in our integrated learning systems in private elementary schools in Alexandria. The paper then concludes with an emphasis on the crucial and efficient use of digital technologies through primary education as a tool to create and conduct art activities in order to help improve children learning in a creative process.
\end{abstract}

\section{Keywords}

Interactive Learning, Creativity, Interactive Visual Art, Younger Students, Technology, Educators

\section{Introduction}

Today, young children are living in a world challenged by an increasing growth of technologies. Educational 
methods have to remotely adjust to these irrevocable changes where a premium must be placed on creativity. Thinking creatively and in, broad, adventurous and clear ways, a well-developed set of higher-cognitive skills is needed. Among which is the ability to reason critically and innovatively. These are currently the most important and necessary tools for the 21st century elementary students to develop for later employment. Teachers are challenged to reconsider the features of efficient, creative learning methods and encouraged to apply innovative ways of teaching in computer-mediated environments to further advance the curriculum. Looking into visual art provides a context particularly well-suited for cultivating creative thinking, because works of art demand thoughtful attention to discover what they have to show and say.

This new way of seeing enables continuous exploration of new ideas and newer artistic teaching methods, and reflects the creative thinking process to improve children learning outcomes (Wright, 2010; Winner et al., 2013; Sharp, 2001). It was said that to design is to invent; "invention" is the conversion of an idea to an artifact; it is more the product of art than science. However, not many educators recognize the efficient role of learning academic subjects in a dynamic visual art setting instead of reading instruction alone as a means of getting younger students to achieve creativity. The mixture of forms in interactive art, which arise from a conjunction of elements of the visual art combined with digital technologies, can provide a methodological foundation that is suitable for interactive digital art.

The article represents the need for a fundamental shift in the way teachers and professionals in the educational field conceive visual art, particularly the way the aesthetics of interactive visual art is represented in the learning practices within our current national education system. Art-based interactive multimedia applications do not seem to have been specifically developed for use by elementary school students; there is even less research regarding proper pedagogy related to the development of appropriate instructional design for digital applications. Initial materials were generated to comprise overviews of research into creativity, art aesthetic, and interactivity in order to identify the inter-relations of visual arts and creativity development in non arts-contexts (e.g. sciences, mathematics, technology, etc.). This article will also discuss how to best decide which applications to bring into educational activity at a classroom level to give younger students the flexibility to display information in different ways and enhance their spontaneous levels of creativity.

\section{Background: Visual Art as "Flexible Informal Tool"}

At the primary level, the visual art is the most securely established of the arts disciplines in elementary schools, and art aesthetic is the bond which gives each area of the curriculum its common purpose (Taylor, 1993). Perkins (1994) and Austerlitz (2008) explicate that visual art is a particularly supportive context that can be associated with interactivity to:

- Sensory anchoring;

- Instant access;

- Personal engagement;

- Dispositional atmosphere;

- Wide-spectrum cognition (visual processing, analytical thinking, posing questions, testing hypotheses, verbal reasoning, and more).

Of course, every art form has a significant part to play; nevertheless, aesthetics percolates each form of the visual arts into specific areas of the school curriculum to evoke thoughts, feelings, and understandings of meaning. Anderson (2004) argued the need for teachers not to impose adult techniques and standards on young children, and articulated the potential of the arts to reform and to inform the broader elementary curriculum so children become more open to new ideas and concepts. In relation to aesthetic considerations, each form of the visual arts can be seen and understood to give further insight and understanding with more opportunities to engage in related practical activities in academic teaching. With a focus on visual art as one of the major forms of arts, attention is drawn on an aesthetic that embraces more the creative mode than the arts to infiltrate the lines separating the disciplines (Abbs, 1987). For example, design is coupled with technology to explore the role and implementation of specific forms of visual art and to link their use to consolidate their place in promoting science and mathematics to stimulate imagination and develop creativity. Thus arts are the characteristic ways in which aesthetic experiences, like creativity, shall be fostered throughout the curriculum (Abbs, 1989; Eysenck, 1975) and aesthetic experience is concerned with increasing conception awareness of line, form, design, and their dynamics. Visual art, science, mathematics, and technology are integrated activities shaped by aesthetic expe- 
riences, in which art is the representation and science the explanation (Taylor, 1993). No doubt, the aesthetic in the relationship of science and arithmetic to arts—nature, form and the artistic — can mutually benefit and enrich each other as imagination and intuition are the main potential of the sciences and mathematics. In scientific concepts young children may be asked to imagine possibilities and forms to visually detect the underlying structure of compositions and envision how theories have been constructed by scientists. From a mathematical angle, perspective in paintings is the best way to geometrically describe many natural theories, and through the intellectual establishment of a constructive connection. This is exemplified by mathematics, the function of the geometrical concepts of point, line, and surface that can be visualized by drawing, and virtually constructed and deconstructed by architecture and design. Arts, therefore, feature more than servicing agencies for a sciencedriven curriculum (Morrison, 2001). When science, mathematics, and arts creatively come together with other instructional activities, and are properly taught through the support of new forms of technological tools, then learning becomes more enjoyable and promptly engages children in the full use of their senses.

Learning ("in" and "through" arts) offers the best kind of unconstrained thinking and informal learning. Visual art training takes a particular art form to imagine the unimaginable; it's more like an image or idea in minds brought into being. In fact, experiencing in appropriate forms of visual art gives a reasonable transfer for younger students to become better at envisioning structures in forms (information content in a painting, a sculpture, etc.) and to look more closely to carefully observing and noticing continual changes in nature (external meaning) (Hetland et al., 2013; Taylor, 1992). Recipients engaged in this kind of disciplined manner over long periods of time become more focused and responsive, coming to terms with the perceptual world. For that reason, learning activities have to be based on artistic interactivity, and designed to be aesthetically attractive to younger students as an analytical, critical, or deconstructive model of interactivity to provide a great deal of interesting information to fit their needs and interests.

A qualitative survey was conducted to investigate the potential role of visual art in pedagogic interactivity as a goal to develop students' creativity at the primary school level. The survey sought to evoke critical thinking, which is often conceived as indivisible from creative thinking. The survey was used to translate the impact of art into traditional learning activities to integrate art, science, mathematics, and technology into a creative setting, in which software applications are developed to a level where interactive aesthetic can transform passive viewers/learners into participants/active learners (Austerlitz, 2008). A common line was also drawn between critical thinking associated with the perception of the interaction-based visual art, and the developmental curve of creative thinking which seemed to increase as a result.

\section{Techno-Visual Art: An Integral Role in Exploration and Discovery}

A discussion based on a questionnaire addressed to science and math teachers, art educators, and IT specialists in private elementary schools in Alexandria, was used as a sample for this study. The questionnaire reflects the subjective opinions of teachers. The questionnaire also revealed much needed professional development activities, specifically design-related activities that would embed interactive art media that adapt well to brainstorming digital humanities activities. The survey shows that an overwhelming percentage of teachers in our primary schools (80\%) considered the lack of ICT (Information Communication Technology) skills, time, and hardware as a barrier. One's use of digital activities and interactive applications depends on whether they are available for free trial or whether they are free access web based applications. They were more likely to agree that bringing in software of this type can be a great way to perform complex tasks in a simulated activity, transform an assignment, and add artistic practices outcomes to a range of disciplines. The teachers noted that based on the emerging trends, children who e-read become more responsive and creative in the interplay between academic content and digital interactive platforms. $75 \%$ of teachers say that smart technologies establish a positive account of dynamic formative interventions. The “doing” may open possibilities for the "seeing”, and interactive visual-based application must be about exploring, drawing out hidden connections and symbolic ideas as a means of expressing and communicating ideas to further practical knowledge of basic processes and materials.

Art educators, as part of the same study, observed that mathematic and scientific ideas are better expressed in dynamic visual arts than in static written or drawn forms; digital applications with multi-modal functions such as video and audio, and aesthetic communicative functions allow children to visualize the interactive, exploratory component of mathematics and architecture by the age of six. It also allows them to have first draft understanding of forms and compositions, and a beginning to organize drawings of the objects with reference to perception. 
As also can be noted, at ages 7 and 10 children become less conventional and increasingly interested in experimenting with unusual forms, color combinations, and compositional arrangements, usually using their creative imagination and are normally able to envision a wider set of relationships around them as they get older. At ages 10 and 12, youngsters' observation increases, as they become more attentive visually about what is being shown in front of them that they ditch their imaginative and creative curiosity. The use of ICT for arts instruction plays an integral role in exploration, knowledge, and discovery; the dynamic visualization is the interactive, exploratory component of academic subject matters (e.g. science, technology, and math) is virtually experienced. Less than $15 \%$ of the respondents said the applications they used were produced and created by themselves. Respondents mentioned that the integration of arts-applications program is expected to work well because of such empowerment that younger students could utter in exploring from the hub of not just a visual static reference but also combined with dynamic content to more fully understand important relationships between form and function. According to respondents, the efficient interaction of mathematics with visual art in combination with smart technology offers a clear perspective on a particular subject and allows learners to conduct lab experiments to manipulate geometric shapes in two- and three-dimensional space, and perform mathematical simulations in an artistically intelligent environment. Nonetheless, only half of the teachers claim that visual arts activities work only with subjects: language arts, reading, and social studies. Few respondents explicated that learning through interactive informative environments is full of controversy, as $15 \%$ claim that a stimulating setting advances much further into informal education which leads into distraction; Moreover, they perceive education as something serious, with no time for interactive art-based activities, which is still seen as the least important. By contrast, more than $75 \%$ of respondents believe that a child can be simultaneously active while engaged in observing and reacting in the process of art related perception in interactive art. They argued that interactive form, content and process mood is an invaluable aid to engaging, analyzing, and responding practice, and younger students shall be used to the idea of translating ideas into different forms as interactive visual arts put that aspect of the feeling into it. Most mentions for collaborations between software designers and ICT specialists to the ongoing development of software applications to create a proper interactive learning pedagogy that is compelling and easy for elementary school students to follow and adapt. They believe that the low tech understanding of visual art interactivity among educators is a barrier and that should be taken into consideration when evaluating the effectiveness of the application on the platforms with which they interacted, and what should be actually integrated. Challenges mentioned for implementing interactive arts integration included the need for time and the proper budget to collaborate develop arts-based content activities from a static medium to an interactive platform.

Combining the results of the discussion into the table below to locate specific forms commonly integrated for training in the visual arts in the elementary curriculum: painting, drawing, sculpture, and architecture which are more beneficial than others in terms of impact on critical thinking and visual perception skills. The table also aims to promote discussion of interactive digital activities associated with visual art; these forms contribute to improve geometric reasoning and develop the ability to mentally envision forms, and observe closely skills that could transfer to the study of science and geometry, or deployed in mathematics (Table 1).

Why those four forms, exactly? What do those four forms have in common with science and mathematics?

Table 1. Visual art forms and creative-related skills.

\begin{tabular}{|c|c|c|}
\hline Visual art & Competences & \\
\hline $\begin{array}{c}\text { Painting } \\
\text { (two-dimensional media) }\end{array}$ & $\begin{array}{l}\text { - Extends visual concepts. } \\
\text { - Forms mental images (imagine the invisible). } \\
\text { - Uses intuitive imagery. }\end{array}$ & $\begin{array}{l}\text { Analyzing } \\
\text { Envisioning and observing } \\
\text { Exploring }\end{array}$ \\
\hline $\begin{array}{c}\text { Drawing } \\
\text { (two-dimensional media) }\end{array}$ & $\begin{array}{l}\text { - Distinguishes between real and imaginary. } \\
\text { - Teaches to analyze, reorganize ideas, and transform them into new images. } \\
\text { - Helps understand scientific concepts. }\end{array}$ & $\begin{array}{l}\text { Observing } \\
\text { Imagining } \\
\text { Understanding }\end{array}$ \\
\hline $\begin{array}{c}\text { Sculpture } \\
\text { (three-dimensional media) }\end{array}$ & $\begin{array}{l}\text { - Extends critical capabilities. } \\
\text { - Develops skills in interpretation. } \\
\text { - Addresses questions of value and quality }\end{array}$ & $\begin{array}{l}\text { Construction } \\
\text { Visualizing } \\
\text { Critically thinking }\end{array}$ \\
\hline $\begin{array}{c}\text { Architecture } \\
\text { (three-dimensional media) }\end{array}$ & $\begin{array}{l}\text { - Helps express a wide range of ideas. } \\
\text { - Introduces concept of space and spatial visualization. } \\
\text { - Improves geometric reasoning. }\end{array}$ & $\begin{array}{l}\text { Critical understanding } \\
\text { Visualizing } \\
\text { Creative thinking }\end{array}$ \\
\hline
\end{tabular}


Most important, what do these forms of visual art achieve for the critical thinking and creativity of younger students, and how can we improve digital application interactivity?

The skills involved in the art domain are very similar to the skills tested in the science and mathematics domains, the relevance of arts experiences benefits to areas like science to understand factual and theoretical nature then grows into deeply sensed experience through interactive practices. These art-forms and scientific contents are closely related, and incorporating the digital environments creates an intimate correspondence between visual and academic language as a form of translation of science, mathematics, etc. into sets of visual languages. In light of the Assessment and Teaching of 21st Century Skills project (AT21CS), arts formulate a core subject, which includes skills such as creativity and innovation, critical thinking and problem solving, communication and collaboration. Authentic Intellectual Work (AIW), criteria for teaching references the ability to maximize expectations for intellectually challenging all students to increase their interest in academic work, provide a common conception of intellectual work of different grade levels and subjects, and equip them to address the complex intellectual challenges of work. Visual arts are clearly gaining ground as a way to make academic subjects learning more innovative. Tsai (2013) recognized involving skills such as creative and critical thinking could grow better thinkers as a crucial part of the creativity process. Rabkin and Redmond (2004) claimed that any arts integrated curriculum meets a high standard of authentic intellectual work and children will naturally be more engaged. Ross (1985) reported that the use of art be an instrument for teaching in-depth understanding of all subjects in the academic curriculum.

Artistic practice is an indispensible tool for strengthening imaginative consciousness and developing creativity, awareness, understanding, and visual knowledge. However, Winner et al. (2013) concluded that integrating the arts improves academic performance and makes children more innovative thinkers has not yet been proven. Winner and Cooper's (2010) findings failed to support the view that creativity is causing academic achievement. Although it has been speculated that creativity and innovation cannot be translated into better general academic achievement based on scores on the kind of tests that children now take in school, it has been stressed on the educational value of learning as a process matter, "to know and understand", such improvement function is due to the effect of visual art experience students received. Undoubtedly, technologies integration would give a vital means of reaching students in and through the arts as investigative methods.

\subsection{Brain Processes \& Creativity}

After considerable debate on creativity, contemporary approach to creativity research has adopted a definition that creativity is the human process leading to novel ideas (Mishra \& Singh, 2010), whereas creative thinking "innovative" encompasses the acts: to inquire, explore, imagine the outcome, take risks, reflect, and innovate and focuses upon the nature of the interaction between the human and medium rather than upon outcomes (Ross, 1985; Erik et al., 2011). Hence, artful educator and teacher should pay great regard on the thinking process and how to engage younger students emotionally, intellectually, and not to settle with one perspective to nourish their natural creativity and adaptability. Ross (1985) identified flexibility as a creative process, and the feature of a creative act is the absence of any rules so children can constantly explore utilizing a particular range of artistic methods, and move freely between making and receiving (maker \& receiver). This in turn enables him to visualize a range of further possibilities within a work in term of another subject area. Abbs believes that when a child feels comfortable making mistakes, and is encouraged to go beyond the context of the formal approaches he has learned, will be genuinely empowered to aesthetically recognize vital links and connections in each aspect. In other words, a child is more likely to learn to notice the discovery in science or simple geometrical nature in mathematics, and to be creative in making a discovery and shaping meaning into expressive and comprehensible forms, when he enjoys the learning process, and is thrilled to know and understand such a thing cannot be a formal thing with rules. In conclusion, creativity is whenever imagination and divergent thinking come first, the ability to reconstruct reality (Wilson, 2014; Wilson \& Myhill, 2013), a process that vitally includes creating originality, not just a copy of the original, but more like mentally envisioning the formation of images which can then guide actions and problem solving.

\subsection{Creative Curriculum a Quest for Innovation}

As we live today in a digitally connected world, 21st century children are more engaged in technology and digital activities than ever. Incorporating digital creative approaches and dynamic representation of conceptual 
forms in academic subjects through visual art in learning activities in primary schools will subtly enhance the student's imagination. Integrating a variety of technologies into visual art reactivates the brain to make mental changes by looking deeper, and in more refined, informed, and systematic ways. Interactive technology can allow teachers to target creativity and stimulate younger students to envisage a whole range of possibilities to be able to determine central ideas, develop, and analyze them in dynamic visual forms. Such processes involve thinking, visualizing and doing. Cassirer (1996) and Kozhevnikov et al. (2013) imply that creativity involves a dynamic procedure of active generation and described technology as "tools of the mind" that have been developed to give the ability to immersively visualize what cannot be seen, reinforce capacity to discover nature (thinking creatively and analytically), and grasp reality in the sense of theoretical comprehension. It was said, if freedom is the heart of creativeness, interactivity is the dialog that occurs between the brain and the thoughts, in which investigation helps them to think more critically about the content-area material, and apply their learning beyond the classroom.

Hence, the key insight of a creative curriculum is the critical exploration; the link between education in the arts, and understanding the aesthetics of digital interactions, which builds a new path towards creative learning methods that should be grounded in the arts to move beyond academic standardized content or formal class teaching methods across all content areas and activities (Sharp, 2001; LaViola, 2007; Rieber, 1991; Walker. et al., 2011). Lately, visual arts initiatives supported by technological tools have been approached in elementary class room teaching, and many studies have been investigating whether learning by visual arts in conjunction with interactive technology may bridge conceptual boundaries between the arts and all other subjects in the academic primary curriculum, such as science, mathematics and technology, to acquire the creative thinking associated with flexible problem solving and innovative skills the children need so as to be imbued with the excitement and thrill of discovery. This process must take place in dynamically interactive ways that involve creative thinking in the context of interactive art. It acquires broad and adventurous thinking that is clear and deep, and organized to make it easier for students to grasp scientific concepts.

This fast changing educational environment requires teachers to have a more secure understanding of the subject they teach to work in partnership with art educators and computer specialists to identify the links and possibilities between visual art and the rest of the curriculum in ways learning could be aesthetically simulated with computing. This is needed to effectively employ visual thinking methods and strategies. Taylor (1993) argues the claim that children aged 9 and over should be taught by subject specialist teachers who would eventually reduce the potential of the arts to inform and per consequence detriment creativity. The new integration of technologies and visual art activities with other scientific subject area in such interactive programs will have to be thought through as a contribution to the creativity development of young children in translating the invisible relation between forms into real world matter. Mathematics, science and computer graphics are moving forward together to produce an interactive aesthetic educational model that is moving beyond the formal structure of a static context.

The author has looked over about 40 well-designed "edtech" applications and web-based art, which were reviewed and rated by educators that can run on multiple platforms, including Microsoft Windows, Apple, or Android, and use graphic aids through computerized-assisted artworks as an aid in science, technology, mathematics comprehension instruction to help younger students build and practice critical thinking skills, solve a numerical equation, visualize and comprehend the content of the problem, and rev up creativity. These applications, in turn, depend on the application platform (e.g., desktop, or mobile web app) they run on to carry out all of the activities in the process, whereas I-learning/web-based platforms must support the interaction between users and systems. The below apps listed in Table 2 are ideal for plain, unconstrained exercises of the imagination, and were also referred to for their simple and visible graphical interface features, in which games are easy to navigate and some have voice-over instructions to guide children through different stages of game play.

The activities on these applications are carried out by educators for constructivist, reflective practices to serve two outcomes: visualizing/constructing mental images and concepts in math-science program to create in the mind of the observer perceptions and senses; meaning into images beyond what can be captured by the static shapes on papers; as well as switching between the imagination and attentional control through visual art; shape further thought and imagery to increase creative and critical thinking, which further affect creativity.

How do aesthetics feed into the practices that we find in interaction apps, and how does creating new relations across disciplines and practices feed into new ways of thinking, doing and acting? Aesthetic in visual art enhances children's aesthetic perception and imagination, and presents significant correlations with children's creative 
Table 2. Interactive Apps, platforms, and creative-related skills.

\begin{tabular}{|c|c|c|c|}
\hline Apps & Skills & Grades & Platforms \\
\hline $\begin{array}{l}\text { Faces iMake—-Right Brain Creativity } \\
\text { iMagine Machine LLC }\end{array}$ & Creativity & Pre-K-5 & iPad \\
\hline $\begin{array}{l}\text { Mystery Math Museum } \\
\text { Artgig Studio }\end{array}$ & Critical Thinking & $1-6$ & iPad \\
\hline $\begin{array}{l}\text { Mystery Math Town } \\
\text { Artgig Studio }\end{array}$ & Critical Thinking & $1-6$ & iPad \\
\hline $\begin{array}{l}\text { DIY Nano } \\
\text { The Lawrence Hall of Science }\end{array}$ & Creativity + Critical Thinking & $2-5$ & iPad, Phone \\
\hline $\begin{array}{l}\text { Toontastic } \\
\text { Launchpad Toys }\end{array}$ & Creativity & K-5 & iPad \\
\hline $\begin{array}{l}\text { Animated Paintings Using Gifs } \\
\text { Art Room }\end{array}$ & Creativity & $5+$ & Website \\
\hline $\begin{array}{l}\text { New Angles on Art/Counting on Art } \\
\text { National Gallery of Art }\end{array}$ & Creativity & $5-12 / \mathrm{K}-8$ & Website \\
\hline $\begin{array}{l}\text { Geoboard } \\
\text { The Math Learning Center }\end{array}$ & Critical Thinking & $2-5$ & iPad, Phone \\
\hline Finger Physics & Creativity + Critical Thinking & $2-5$ & Android, Pad, iPhone \\
\hline $\begin{array}{l}\text { Dexteria Dots } 2 \\
\text { BinaryLabs, Inc. }\end{array}$ & Critical Thinking & $\mathrm{K}-3$ & iPad, iPhone \\
\hline $\begin{array}{l}\text { The Land of Venn-Geometric Defense } \\
\text { iMagine Machine LLC }\end{array}$ & Critical Thinking & $1-4$ & iPad, iPhone \\
\hline $\begin{array}{l}\text { Ink Blot Monsters } \\
\text { Art Room }\end{array}$ & Creativity & $5+$ & iPad \\
\hline $\begin{array}{l}\text { Sago Mini Doodlecast } \\
\text { Art Room }\end{array}$ & Creativity & $\mathrm{K}-4$ & iPad \\
\hline $\begin{array}{l}\text { Interaction of Color } \\
\text { Yale }\end{array}$ & Creativity & $8-12$ & iPad \\
\hline National Geographic Kids & Creativity + Critical Thinking & $1-6$ & Website \\
\hline $\begin{array}{l}\text { Exploratorium } \\
\text { Destination Modern Art }\end{array}$ & Creativity + Critical Thinking & $\mathrm{K}+$ & Website \\
\hline
\end{tabular}

thinking which in turn has been noted to be correlated with children's creativity (Lee, 2015). It has been suggested that young children perform significantly above average in intellectual and creative areas when they spend more time learning through interactive activities in which the artistic realm is integrated; they are opened to distinctive opportunities for exploring the many intersections between affect, perception, and exploration.

In accordance with interactive technologies, the following factors must be incorporated in computer-mediated environments to create well-tempered educational applications that aspire towards visual art:

- The software must be designed to facilitate integration.

- Richness of content (interesting, exciting, and valuable).

- Computer-generated graphics, data, and performative works that use digital media are adapted to fit their needs and interest.

- Simple translation from outline concepts to working interactive images; interconnected language more logical and more primitive.

- Content material is developed based on aesthetics, art criticism, and methods of inquiry from the visual art disciplines to serve the curriculum objectives for the different educational settings.

- Content has also to be dynamic, interactive and re-formally convey meaning as action to prevent distraction.

- Concepts and principles are visually represented, interpreted by a specific form of art, and followed by i-Apps.

- Digital activities should be deeply aesthetic in nature and fused with drawing, painting, etc.

- Interactive visual art incorporating more accessible content and components including, animation, modeling, art direction, textures, etc., to be used to generate or communicate abstractions. 
The goal of interactivity should be based on exploratory strategies; discovery and reflection on content; involvement; active and interactive.

\section{Conclusion}

Technological innovations combined with the visual arts provide new possibilities for training the mind in the process of producing new ideas naturally to transfer creative thinking to other content to increase creativity. It is now possible to interact with new developments to more clearly locate the potential place of the dynamic nature of visual arts, and its relevance to the creative act to be vividly illustrated in the capacity of younger students to employ their creative ability to learn at heightened levels of involvement and originate new ideas. This overview study has led the author to the following conclusions:

1) Most i-Apps are rather limited and standardized to be applied to enhance language literacy; Apps or web-based activities are to be delivered to stimulate the interconnection of content and related activities in the materials.

2) Software programmers ought to focus their effort on the effectiveness of interacting with new technologies which involves imaging, modeling, planning, making, and link them with the aesthetic field of making, presenting, responding and evaluating in order to communicate their design as clearly, concisely and graphically as possible.

3) Software must be designed to facilitate full integration of visual art with other instructional activities so younger students are able to determine central ideas or themes while also improving their imagination.

4) Designers of interactive learning applications should give great consideration to include artistic pedagogical agent in their software application because of their positive effects on younger students' imagination and unleashing creativity.

5) Theories and concepts are best learnt in a dynamic context where teachers can relate ideas to practical implications so younger students can interact creatively with these.

6) Teachers should also be involved in programming to ensure that technological medium and pedagogy have been interacted at a deep level where cross-arts implications are dynamically implemented, and relevant to the whole curriculum to promote creativity.

7) Also teachers should benefit from the insight of art educators, and work on encouraging younger students' creativity across all subject areas and give them opportunities to freely contribute to their own learning.

\section{Recommendation}

It is beneficial to build dynamic curriculum thinking from that which is built into most national traditional elementary schools methods. More studies are needed to prove that learning by visual art in a techno-interactive setting is efficial for its transformative effect on a variety of factors including creative abilities.

\section{References}

Abbs, P. (1987). Living Powers: The Arts in Education. London: Falmer Press.

Abbs, P. (1989). A Is for Aesthetic: Essays on Creative and Aesthetic Education. London: Falmer Press.

Austerlitz, N. (2008). Unspoken Interactions: Exploring the Unspoken Dimension of Learning and Teaching in Creative Subjects. London: The Centre for Learning and Teaching in Art and Design.

Erik, D., Markus, B., Michael, G. P., \& Greg, R. O. (2011). Rational versus Intuitive Problem Solving: How Thinking “Off the Beaten Path” Can Stimulate Creativity. Psychology of Aesthetics, Creativity, and the Arts, 5, 3-12. http://dx.doi.org/10.1037/a0017698

Eysenck, H. J. (1975). Educational Consequences of Human Inequality. London: Dent.

Hetland, L., Winner, S., \& Sheridan, K. (2013). Studio Thinking 2: The Real Benefits of Visual Arts Education. New York: Teachers College Press.

Kozhevnikov, M., Chen, J. Y., \& Blazhenkova, O. (2013). Creativity, Visualization Abilities, and Visual Cognitive Style. British Journal of Educational Psychology, 83, 196-209. http://onlinelibrary.wiley.com/doi/10.1111/bjep.12013/full http://dx.doi.org/10.1111/bjep.12013

Lee, K., \& Jun, J. (2015). Developmental Characteristics of Creative Thinking Ability and Creative Personality of Elementary School Children in Korea. Advanced Science and Technology Letters, Education, 92, 46-51. 
Morrison, R. G., \& Wallace, B. (2001). Imagery Vividness, Creativity and the Visual Arts. Journal of Mental Imagery, 25, 135-152. http://www.xunesis.org/publications/morrison\%26wallace_JMI_2001.pdf

Mishra, L. K., \& Singh, A. P. (2010). Creative Behaviour Questionnaire: Assessing the Ability of Managers to Produce Creative Ideas. Journal of the Indian Academy of Applied Psychology, 36, 115-121. http://medind.nic.in/jak/t10/i1/jakt10i1p115.pdf

Perkins, D. N. (1994). The Intelligent Eye: Learning to Think by Looking at Art. Santa Monica, CA: J Paul Getty Trust.

Rabkin, N., \& Redmond, R. (2004). Putting the Arts in the Picture: Reframing Education in the 21st Century. Chicago, IL: Columbia College.

Taylor, R. (1992). The Visual Arts in Education: Completing the Circle. London: The Falmer Press.

Taylor, R., \& Andrews, G. (1993). The Arts in the Primary School. London: The Falmer Press.

Tsai, K. C. (2013). Being a Critical and Creative Thinker: A Balanced Thinking Mode. Asian Journal of Humanities and Social Sciences (AJHSS), 1, 1-9. http://ajhss.org/pdfs-1/Being\%20a\%20Critical\%20and\%20Creative\%20Thinker.....pdf

Walker, C. M., Winner, E., Hetland, L., Simmons, S., \& Goldsmith, L. (2011). Visual Thinking: Art Students Have an Advantage in Geometric Reasoning. Creative Education, 2, 22-26. http://dx.doi.org/10.4236/ce.2011.21004

Wilson, A. (2014). Creativity in Primary Education. London: SAGE Publications Ltd.

Wilson, A. C., \& Myhill, D. A. (2013). Teachers’ Views of Creativity. Thinking Skills and Creativity, 10, 101-111. http://dx.doi.org/10.1016/j.tsc.2013.07.002

Winner, E., \& Cooper, M. (2000). Mute Those Claims: No Evidence (Yet) for a Casual Link between Arts Study and Academic Achievement. Journal of Aesthetic Education, 34, 11-75. http://dx.doi.org/10.2307/3333637

Winner, E., Goldstein, T., \& Vincent, S. (2013). Art for Art's Sake? The Impact of Arts Education (Educational Research and Innovation). OECD Publishing, Paris. http://dx.doi.org/10.1787/9789264180789-en 